\title{
Quotations in Headings
}

1. (2.1) “The Question Is -Said Humpty Dumpty ..." (TTLG, 224) - 26

2. (2.2) "He Was Part of My Dream ..." (TTLG, 285) - 40

3. (2.3) "The Magic Words Shall Hold ..." (TTLG, 139) - 54

4. (3.1) "The More Head-Downwards I Am ..." (TTLG, 254) - 68

5. (3.2) "So You Are Another Alice" (M. Cohen 1989b, 196-197) - 89

6. (3.2.3) "Impenetrability! That's What I Say!" (TTLG, 224) - 97

7. (3.3) "Which Do You Think It Was?" (TTLG, 285) - 99

8. (4.1) "Is This an Extempore Romance ..." (M. Cohen 1995, 91) - 114

9. (4.1.2) "The Poignant Love Song ..." (Rackin 1982, 38) - 117

10. (4.1.3) "Still She Haunts Me" (TTLG, 287) - 120

11. (4.1.4) "Lolita Has Been Safely Solipsized" (Nabokov 2000, 60) - 122

12. (4.2) "What Are Little Girls Made of? ..." (Collingwood 1898, 381) — 127

13. (4.3) "What Is the Use of a Book ..." (AAIW, 11) — 138

14. (4.3.2) "Tut, Tut, Child! ...” (AAIW, 95) — 144

15. (5.1) "You May Call It 'Nonsense' ..." (TTLG, 171) - 148

16. (5.2) "But There's one Great Advantage in It ..." (TTLG, 206) - 161

17. (5.2.2) "And the Rule Is Jam Tomorrow ..." (TTLG, 206) - 168

18. (5.3) "It Always Makes One a Little Giddy ..." (TTLG, 206) — 172 
